\title{
American Pediatric Society Presidential Address 1992: Genetics-The Science and Medicine of the Future
}

\author{
VINCENT A. FULGINITI
}

One of the privileges of the presidency of the American Pediatric Society is the chance to select a topic for the membership and guests at the annual meeting. I've chosen what I consider to be the latest breakthrough, genetic science and medicine.

We can all imagine thresholds of discovery and application in medicine that have forever changed the way we think and behave. In my specialty, infectious diseases and immunology, a series of discoveries and observations changed the medical world. We can think of Semmelweiss, Lister, Walter Reed, and Ehrlich as examples. The last of these reminds us of the introduction of antibiotics. Some of our members in this room, scientists and physicians, experienced the wonder and expectation that was occasioned by the introduction of sulfa drugs and penicillin, harkening the era of specific therapy for infectious diseases. That threshold changed our behavior from watchful waiting to specific action and has spawned many decades of investigation and clinical application.

Enders, Weller, and Robbins' discovery that polio viruses could be cultivated in vitro opened the era of modern immunization theory and practice, which has led to the elimination of smallpox and dramatic reduction in childhood and adult infectious diseases, forever changing the lives of millions. We still pursue the science and medicine that this particular threshold enabled.

Ogden Bruton's observation of immunodeficiency caused by relative absence of gamma globulins in a single child's blood revolutionized our concept of immunity and continues to spur science and medicine to further exploration and application.

I believe that we are on a new threshold that will similarly forever change the way we think and act in both the laboratory and the clinic. For this reason, I selected this topic for the Presidential Symposium. This symposium will explore the genetic breakthrough and herald for the visionaries in this audience the ground on which they will add to our knowledge and modify our methods for diagnosis and treatment in pediatrics.

By way of introduction, I would like to briefly review some important historical aspects of our understanding and application of genetic principles. For physicians of my vintage, the revolution in genetics has spanned mendelian concepts through unraveling of the genetic code, identification of specific gene defects, and the immediate prospect of genetic alteration of disease. The march of science in this area has been swift and astounding in both our understanding of basic mechanisms and application to the clinical arena. Not unexpectedly, the rapidity of discovery and utility has engendered dilemmas for science and medicine, ranging from the appropriateness of allocation of precious resources to this quest to questions of propriety in the clinical use of available knowledge and techniques. This session of the American Pediatric Society's program will be devoted to exploration of some of the aspects of development of genetic information and its application.

One can recount history in a number of ways. I've chosen to list the major steps along the way as one way of chronicling discovery and use, and also to use a more pediatric method, by citing the changes in one of the standards of knowledge in our discipline, Nelson's Textbook of Pediatrics (Fig. 1).

l've borrowed heavily from the history as outlined by J. M. Connor and M. A. Ferguson Smith in their 3rd edition of Essential Medical Genetics, Blackwell Scientific Publications, Boston, 1991.

This figure depicts the major events from the discovery of the cell in 1839, believed them to be the basic unit of life, to unraveling the structure of DNA.

Three classic discoveries from disparate disciplines resulted in focus on microscopic elements to observations for the entire population. The cell was identified 153 years ago as the basic unit of life. Shortly thereafter, Darwin and Mendel made more global observations that forecast the role of genetics in determining changes in individuals and populations over time and in predicting characteristics.

Mendel's observations of crossbreeding in garden peas led him to conclude that heredity was governed by discrete pairs of hereditary elements, or that it was particulate, in contrast to previous beliefs that parents' characteristics were "blended" in offspring. His astute observations were made without the knowledge of the mechanism by which they were engineered, making them even more remarkable in conception.

Although it was known that the sperm and egg were the elements of transmission of hereditary traits, the discovery of the chromosome and the human gene in the early part of this century truly opened the era of subcellular focus on development of organisms, including the human. The observation in 1903 that chromosomes behaved as Mendel predicted hereditary elements should act led to further inquiry into mechanisms. At this time, the focus was on the nucleus of the cell without the ability to peer beyond that level. Both protein and nucleic acid were present in nuclear material, and investigators could not sort out which was responsible for genetic transmission.

\begin{tabular}{|lll|}
\hline \multicolumn{3}{c}{ MILESTONES IN GENETICS } \\
1839 & CELL-BASIC UNIT & SCHLEIDEN/SCHWANN \\
1859 & EVOLUTION & DARWIN \\
1865 & "CLASSICS" & MENDEL \\
1903 & CHROMOSOME & SUTTON, BOVERI \\
1911 & HUMAN GENE & WILSON \\
1944 & DNA ROLE & AVERY \\
1949 & SEX CHROMATIN & BARR \\
1953 & DNA STRUCTURE & WATSON/CRICK \\
\hline
\end{tabular}

Fig. 1. 


\begin{tabular}{|lll|}
\hline \multicolumn{3}{c}{ MILESTONES IN GENETICS } \\
1956 & HGb SEQUENCE & INGRAM \\
1956 & 46, NOT 48 & TJIO/LEVAN \\
1959 & TRISOMY 21 & LEJEUNE \\
1961 & X-INACTIVATION & LYON \\
1961 & GENETIC CODE & NIRENBERG \\
1967 & TK ON CH 17 & WEISS/GREEN \\
1970 & BANDING & CASPERSON \\
1970 & GENE SYNTHESIS & KHORANA \\
1973 & HLA & TERASAKI \\
\hline
\end{tabular}

Fig. 2.

\section{MILESTONES IN GENETICS}

$\begin{array}{lll}1977 & \text { 1ST CLONED GENE } & \text { SHINE } \\ 1977 & \text { SOMATOSTATIN } & \text { HAKARA } \\ 1978 & \text { 1ST DNA DX } & \text { KAN } \\ 1985 & \text { CF GENE-CH 7 } & \\ 1985 & \text { DNA FINGERPRINT } & \text { JEFFREYS } \\ 1987 & \text { LINKAGE MAP } & \text { (MANY) } \\ 1989 & \text { HUMAN GENOME } & \text { (MANY) }\end{array}$

Fig. 3.

\section{J. WARKANY, IN:}

NELSON, TEXTBOOK OF PEDIATRICS, 6th ed., 1954

"In man, the nuclear substance of the zygote and of all the somatic cells derived from it contains $\mathbf{4 8}$ chromosomes. the carriers of the genes."

Fig. 4.

Additional incremental discoveries were made in the interval between 1903 and the DNA era. Investigations with pneumococci demonstrated that nucleic acid was capable of transforming rough strains of this organism into smooth strains, thus identifying the chemical nature of inheritance and establishing the nucleic acids as the focus for future research. Further investiga-
J. WARKANY \& F.C. FRASER, IN:

NELSON, TEXTBOOK OF PEDIATRICS, 7th ed., 1959

"Recently, some investigators have asserted that man has $\mathbf{4 6}$ chromosomes, but this count has not generally been accepted."

Fig. 5.

J. WARKANY \& F.C. FRASER, IN:

NELSON, TEXTBOOK OF PEDIATRICS, 8th ed., 1964

"In man, the sperm and egg (gametes) each carry a set of twenty-three chromosomes, the fertilized egg and the somatic cells derived from it by mitosis therefore contain two such sets of a total of forty-six chromosomes"

"According to the present concept, the polypeptides that constitute the body's proteins are synthesized on the surfaces of cytoplasmic particles of RNA called ribosomes ... the case of sickle cell anemia where a single gene difference was shown to produce a difference in the beta chain of the hemoglobin molecule; the 6th amino acid from the C-terminal ..."

Fig. 6.

I. A. UCHIDA, IN:

VAUGHAN \& MCKAY (EDS), NELSON TEXTBOOK OF PEDIATRICS, 10th ed., 1975

"Protein structure and function are genetically determined."

"...the structure of the DNA determines the amino acid sequence."

"The sequence of bases in the DNA constitutes a code..."

"For most genetically controlled variations in man the underlying biochemical change has not been identified, and one may think of the gene simply as a locus on a chromosome that carries an instruction regarding a particular characteristic or trait of the organism."

Fig. 7.

tions began to unravel the composition of nucleic acids, but not until the remarkable intuition of Watson and Crick in determining the structure of DNA did the door open to dizzying progress in our understanding of genetic mechanisms (Fig. 2).

In rapid order since their epochal conceptualization just 39 years ago, investigators began to sort out the molecular structure of proteins, the mechanism of the genetic code, and the correct number of chromosomes to be identified in the human, followed by dissection of the chromosome into its component parts, learning how the code in DNA was translated into RNA and how the message was delivered correctly and incorrectly (Fig. 3).

Analytic and synthetic methodology permitted rapid advances in ferreting out individual gene functions and defects and, ulti- 


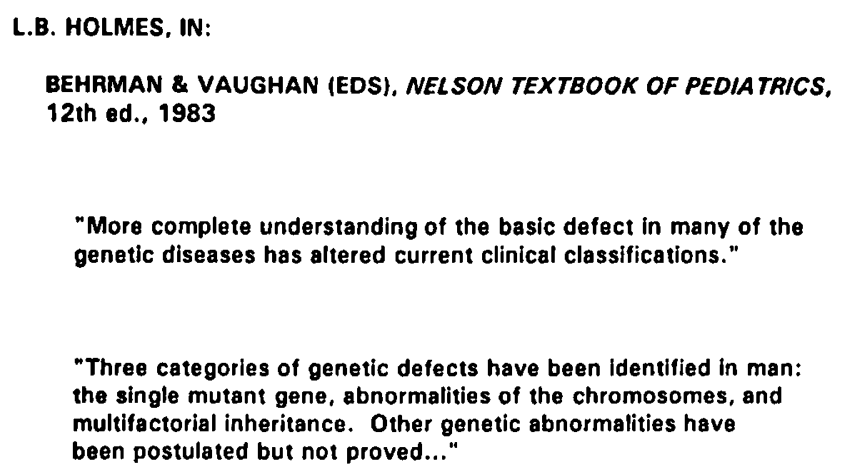

"More complete understanding of the basic defect in many of the genetic diseases has altered current clinical classifications."

"Three categories of genetic defects have been identified in man: the single mutant gene, abnormalities of the chromosomes, and multifactorial inheritance. Other genetic abnormalities have been postulated but not proved..."

Fig. 8.

M.A. ZASLOFF, IN:

BEHRMAN (ED), NELSON TEXTBOOK OF PEDIATRICS 14 th od., 1992

"Each human somatic cell contains two copies of the entire human genome, amounting to 6 billion base pairs of DNA. DNA is a double-stranded helix, each "step" of the helix comprising a base from one strand bonded to that from the other (a base pair) ..."

Fig. 9.

mately, in the desire to map the entire genome, identify all human gene function, and put that knowledge to work in science and human disease prevention and cure. Along the way, scientists have learned how to "engineer" genetics by manipulating DNA in vitro, by discovery of important enzymes that led to the ability to undertake recombinant methods, by synthesis and cloning of human genes, such that by last year more than 1000 human structural genes had been cloned and thousands of DNA sequence segments had been characterized.

We will shortly hear of the impact of each of these steps in upto-date summaries of where we are and where we are going.

Before we proceed, I have chosen Nelson's Textbook of Pediatrics as a more "pediatric" reference to the history of genetics. Many of us in this room have used this text as an educational guide in our careers, and I believe the excerpts I will show also document the march of knowledge in genetics. I've selected text from the 6 th through the current 14 th edition to chronicle the changes in a more immediate way. These editions parallel my own career in pediatrics and have served as a personal guidepost to the changes (Figs. 4-6).

In my days in medical school, we counted 48 chromosomes and my teachers resisted the notion that there were 46 , as suggested by Tjio and Levan. As we can see, as subsequent editions of Nelson were prepared, initial skepticism gave way to certainty in just 11 years (Figs. 7-9).

After resolution of the number, the various authors depicted the growing knowledge of the intricacies of the genetic process by their choice of language to describe the then current state of knowledge, culminating in the just released 14th edition, which is elaborate in its description of modern understanding. One can hardly wait for the 15 th edition, which surely will describe the next era, promising to be the most exciting in the time span I have covered.

When I began my career in infectious diseases, we established the etiology of some infections by injecting the chorioallantoic sac of fertilized hen's eggs to identify viruses, a very crude method. Today, for many of these disease agents, we use the polymerase chain reaction, which multiplies and detects tiny fragments of genetic material from infectious agents and provides a road map to infection based on the faintest of footprints. We have seen the introduction of diagnostic techniques in hospital laboratories, such as DNA probes, that are dependent on genetic methodology, and we are beginning to experience correction of genetic defects using molecular genetic techniques.

Just recently, Nabel and coworkers at the University of Michigan announced that FDA permission had been granted for the first clinical trial in which a therapeutic gene will be injected directly into patients. This treatment is intended to place the gene directly into malignant melanoma tumors of patients who have not responded to standard treatment. Previous efforts in other institutions have focused on replacing genes in the cells removed from the patient and then administering the altered cells back into the same patient; for example, the work of Anderson and colleagues at NIH in patients with congenital immunodeficiency.

Finally, l've assembled from my own reprint file montages of selected titles of scientific articles, professional story headings, and popular media headlines to illustrate the impact that genetics has had on science, medicine, and ethics as an introduction to the talks that follow.

We are on the threshold of another major shift in science and medicine, a shift in knowledge and utility that will alter your behavior in the laboratory and with your patients. Visionaries in this audience will contribute to these changes, such that we will not recognize the descriptions in the 20th edition of Nelson's Textbook of Pediatrics in the next century, using today's language and understanding. It is an exciting time to be in science and medicine, and today we'll learn of some of what the future may hold for us. Thank you. 